Fecha de recepción: diciembre 2010

Fecha de aceptación: julio 2011

Versión final: septiembre 2013

\section{Redes sociales, lenguaje y tecnología Facebook. The 4th Estate Media?}

Vanina Levato *

Resumen: Desde siempre el hombre ha tenido la necesidad constante de comunicarse con sus pares, de expresar sus ideas, sentimientos, de dejar, en definitiva, huella de sí mismo.

Hoy en día asistimos a una Revolución Tecnológica que implica mucho más que la búsqueda por satisfacer cada vez mejor sus vínculos comunicacionales. Por eso es que los avances en los procesos comunicativos ligados a la evolución tecnológica nos permiten hablar de Tecnologías de la Información y la Comunicación.

Dentro de estas Tecnologías observamos un fenómeno por demás significativo: Las Redes Sociales. Estas han ganado un lugar de una manera vertiginosa tornándose en promisorios negocios para empresas y sobretodo en lugares para encuentros humanos.

Internet concentra una variedad de tecnologías que potencian el intercambio y la colaboración entre los usuarios, fomentando de esta manera una creciente cantidad y variedad de redes, signadas por la interacción que es, sin lugar a dudas, una de las características definitorias de las mismas.

Las Nuevas Tecnologías de la Información y la Comunicación conquistan el espacio mediatizado en donde la palabra escrita logra, nuevamente, una importancia decisiva, que otrora había sido desplazada por la reelevancia de lo audiovisual.

Palabras clave: influencia - información - medios - poder - redes sociales.

[Resúmenes en inglés y portugués en las páginas 76-77]

${ }^{(*)}$ Licenciada en Ciencia Política (UBA, 2004). Diploma de Honor. Actualmente se desempeña en la Secretaría de Culto dependiente del Ministerio de Relaciones Exteriores, Comercio Internacional y Culto.

Todos los medios son metáforas activas por su poder de traducir la experiencia en formas nuevas.

Marshall Mc Luhan

Para comprender un poco el fenómeno de las Redes Sociales cabe citar en principio alguna definición básica que nos permita saber, qué son y cómo funcionan en Internet.

Las redes vienen dadas por diversas circunstancias dentro de una misma organización, ya sean, 
por filiación, por conocimiento, por contexto o por demanda. No vamos a ahondar en lo que implica cada una de ellas ya que excedería a los propósitos de este trabajo. Sólo diremos que las redes sociales por filiación son aquellas que se generan de forma espontánea en los grupos y cuya presencia imprime un clima de camaradería e identificación, mientras que las que expresan intereses propios de la organización pero con un alto grado de interés personal y se generan para agregar valor a los procesos, mejorarlos o crearlos se denominan redes sociales por conocimiento. Las redes por contexto o demanda responden a las funciones propias vinculadas a un cargo o a un grupo de ellos, la misma labor genera la integración de estas redes y las pone en movimiento. La empresa es quien marca la pauta de acuerdo a sus intereses y objetivos.

Las redes de contactos sociales son espontáneas y no existe una metodología específica para crearlas. Este tipo de redes serán nuestro objeto de estudio ya que la presencia éstas es de una magnitud tal que se las puede tomar como soportes o sostenes sociales para las personas que conviven en una comunidad dada. Las mismas, han invadido el mundo como respuesta a una necesidad natural de las personas de estar conectadas con otras. La comunicación dinámica sencilla y rápida que se da entre los miembros de una red permite sacar un mejor provecho de los recursos que poseen los individuos que forman parte de la misma.

Existen múltiples definiciones de Redes Sociales. Sin embargo, nosotros utilizaremos la otorgada por Félix Santos, que la concibe desde un punto de vista analítico, es decir como un conjunto de puntos (actores sociales) vinculados por una serie de relaciones que cumplen determinadas propiedades. Las redes sociales gozan de una estructura y una morfología propia, cuyas cualidades, evidencian importantes aplicaciones para el análisis e interpretación de las conductas sociales. Otros autores consideran a la red social al conjunto de individuos, que pueden ser personas o empresas que están relacionados entre sí por algún interés común, que poseen un sentido subjetivo de pertenencia hacia la misma y que mediante acciones organizadas específicas se desarrolla un tejido o red en el que se actúa en pro del bienestar de esa comunidad. A fin de cuentas, si de las redes de las que hablamos son las que forman las personas vinculadas unas con otras, la sociedad siempre ha sido una red. Hay, sin embargo,

... dos elementos nuevos relacionados con esta cuestión que todo el mundo entiende intuitivamente. Por un lado, Internet y su consecuencia más directa: la eclosión de una nueva esfera de relación social que pone en contacto a millones de personas cada día. Por otro, la aparición en los últimos años de una amplia literatura sobre redes aplicada a todos los campos, desde la física o la biología hasta la economía, con toda su inevitable secuela de libros de divulgación, aplicaciones al marketing y juegos publicitarios (de Ugarte, 2007: 29).

Las redes sociales que pueden formarse así son inmensas debido al dinamismo y la evolución de las mismas impulsadas por las actividades de sus componentes. 


\section{Breve reseña de los espacios sociales}

Estos sitios o espacios sociales nacen luego de la caída de las puntocom en el 2001. En el año 2002 aparece el primer sitio capaz de generar círculos sociales: Friendster.

En mayo de 2002 nace el sitio de publicación de fotografías Fotolog.com, y ya en febrero del 2005 superaba el millón de usuarios. El término fotolog (o fotoblog) originalmente se refería a una variante de weblog para la publicación de imágenes.

En el 2003 nace MySpace, la segunda web más visitada de Internet. Este espacio suele definirse como "un lugar de amigos", donde es posible chatear, mandar mensajes, crear blogs, invitar a amigos a participar, e incluso personalizar la página, subir fotos y videos.

LinkedIn es una red social cuyo objetivo es hacer conexiones de tipo profesional entre personas y entre personas y empresas, también lanzada en el 2003. Así, empezamos a tener redes sociales de diversas naturalezas: con orientación específica (LinkedIn para los contactos profesionales o Match.com para contactos sentimentales) En el mismo año comenzó a funcionar del.icio.us, un servicio de gestión de marcadores sociales en la Web.

En febrero de 2004 fue lanzado el sitio Facebook. La fecha de lanzamiento de esta red social quedó registradael4defebrerode2004.LasedecentralseencuentraenPaloAlto,California(EE.UU.) Posee más de 700 empleados según la información obtenida hasta noviembre de 2008. Se clasifica como un sitio que brinda servicios de red social en el que se requiere registrarse para ingresar al mismo. Esta red social fue creada originalmente para estudiantes de la Universidad de Harvard, aunque en la actualidad está abierta a cualquier usuario que quiera ser parte de ella. Es un espacio que permite publicar información personal y profesional, fotos, chatear y ser parte de grupos según intereses personales. Facebook es uno de los sitios Web más visitados del mundo.

Hay sólo tres miembros en la dirección de Facebook y son Thiel, Zuckerberg y un tercer inversor llamado Jim Breyer, procedente de una empresa de capital de riesgo llamada Accel Partners. Thiel invirtió 500.000 dólares en Facebook cuando los estudiantes de Harvard Zuckerberg, Chris Hughes y Dustin Moskowitz fueron a su encuentro en San Francisco en junio de 2004. Poco después lanzaron el portal. Según se informa, Thiel posee actualmente el 7\% de Facebook, que, de la valoración actual de 15 billones de dólares, valdría más de 1 billón.

En mayo de 2006, la red de Facebook se extendió con éxito en la India, con apoyo de institutos de tecnología de aquel país.

En junio de 2006, hubo un acuerdo con iTunes Store para que el mismo conociera los gustos musicales de los usuarios y ofrecer así un enlace de descarga en su propio sitio. En agosto de 2006, Facebook agregó universidades en Alemania e Israel a su red. También introdujo la importación de blogs de Xanga, LiveJournal o Blogger. Desde septiembre de 2006, Facebook se abre a todos los usuarios del Internet. En julio de 2007, Facebook anunció su primera adquisición, Parakey, Inc. de Blake Ross y de Joe Hewitt.

A fines de octubre de 2007 la red de redes vendió una parte, el 1,6\%, a Microsoft a cambio de doscientos cuarenta millones de dólares con la condición de que Facebook se convirtiera en un modelo de negocio para marcas de fábrica en donde se ofrezcan sus productos y servicios, según los datos del usuario y del perfil de éste. Facebook supuso, en este entorno, toda una fuerza renovadora al ofrecer una API (Application Program Interface) que permitiese a los desarrolladores brindar aplicaciones de todo tipo a su base de usuarios. La llamada, a pesar de forzar a los programadores a escribir en un lenguaje no completamente estándar, (FBML, o Facebook Markup Language en 
lugar del habitual HTML, Hyper Text Markup Language), fue todo un éxito de crítica y público. Esta adquisición valoró a Facebook en quince mil millones de dólares, aunque el consenso de los analistas fuera que esta cifra superaba el valor real de la empresa. Para Microsoft no se trataba sólo de una inversión financiera, sino también de un avance estratégico en Internet. En julio de 2009, Mark Zuckerberg, hizo público que Facebook había alcanzado los 250 millones de usuarios El 15 de septiembre del mismo año anunció que superaba los 300 millones y el 2 de diciembre que ya contaba con más de 350 millones. También se ha puesto en marcha Facebook en español, extendiéndose a los países de Latinoamérica. Casi cualquier persona con conocimientos informáticos básicos puede tener acceso a todo este mundo de comunidades virtuales. Durante el mes de marzo de 2010 La red social Facebook logró un "hito histórico", fue el sitio más visitado por los estadounidenses en la última semana. Según los resultados, la red de Mark Zuckerberg tuvo un crecimiento del $185 \%$ durante los últimos siete días, con respecto al mismo periodo de 2009. Mientras tanto las visitas que recibió Google se incrementaron apenas un 9\%.

\section{Facebook - Puertas adentro}

Ahora bien, si uno ingresa al sitio, ( www.facebook.com http://es-es.facebook.com/ ) se encuentra con los siguientes servicios ofrecidos por esta red social:

Lista de Amigos: En ella el usuario puede agregar a cualquier persona que conozca y esté registrada, siempre que acepte su invitación. Se pueden localizar amigos con quienes se perdió el contacto o agregar otros nuevos con quienes intercambiar fotos o mensajes. Para ello, el servidor de Facebook posee herramientas de búsqueda y de sugerencia de amigos.

Muro: el muro es un espacio en cada perfil de usuario que permite que los amigos escriban mensajes para que el usuario los vea. Sólo es visible para usuarios registrados y permite ingresar imágenes y poner cualquier tipo de logotipos en la publicación. Una mejora llamada supermuro permite incrustar animaciones flash, etc.

Fotos: Según Facebook, hay: 5 mil millones de fotos de usuarios y 160 terabytes de almacenaje.

Regalos: los regalos o gifts son pequeños íconos con un mensaje. Los regalos dados a un usuario aparecen en la pared con el mensaje del donante, a menos que el donante decida dar el regalo en privado, en cuyo caso el nombre y el mensaje del donante no se exhibe a otros usuarios. Una opción "anónima” está también disponible, por la cual cualquier persona con el acceso del perfil puede ver el regalo, pero solamente el destinatario verá el mensaje.

Juegos: la mayoría de aplicaciones encontradas en Facebook se relacionan con juegos de rol, juegos parecidos al Trivial Pursuit o pruebas de habilidades.

Aplicaciones: Son pequeñas utilidades. 
Grupos y Páginas: Es una de las utilidades de mayor desarrollo reciente. Se trata de reunir personas con intereses comunes. En los grupos se pueden añadir fotos, vídeos, mensajes, etc. Las páginas, se crean con fines específicos y a diferencia de los grupos no contienen foros de discusión, ya que están encaminadas hacia marcas o personajes específicos y no hacia ningún tipo de convocatoria.

Cabe aclarar que los grupos también tienen su normativa, entre la cual se incluye la prohibición de grupos con temáticas discriminatorias o que inciten al odio y falten al respeto y la honra de las personas. Si bien esto no se cumple en muchas ocasiones, existe la opción de denunciar y reportar los grupos que vayan contra esta regla, por lo cual Facebook incluye un link en cada grupo el cual se dirige hacia un cuadro de reclamos y quejas.

Constan, sin embargo, numerosas denuncias de censura contra Facebook. Sin ir más lejos, el argentino Juan Faerman, autor del libro Faceboom (2009), que analiza este fenómeno de masas que es la red social desde una perspectiva de humor e ironía, denunció que su perfil fue borrado, sin previo aviso, de la plataforma.

Más allá de Faerman los principales damnificados son los fans y el público que se los priva del derecho a la información, sobre todo porque en este caso puntual, Faerman no violó ninguno de los términos y condiciones que fija Facebook a los usuarios. El perfil no era con fines económicos ni de lucro ni se manifestó odio racial o violencia. Simplemente es una interpretación y una mirada del fenómeno. En esos casos, Facebook puede notificarte que el contenido que subsiste no corresponde y suprimir esa parte, pero la censura está prohibida

Más allá de lo expuesto en los párrafos precedentes, los grupos y páginas son, sin lugar a dudas, una de las aplicaciones más importantes de esta red social, que nos permite adentrarnos en nuestro tema en cuestión ya que, después de su traducción a idiomas diferentes del inglés, Facebook no sólo ha crecido en usuarios, sino que ha transformado la forma en la que las personas utilizan Internet poniendo de manifiesto la capacidad inagotable de innovación de las industrias de información y entretenimiento.

Cabe agregar que los individuos o miembros son llamados "actores" o "nodos" en las publicaciones que detallan el funcionamiento de las redes sociales, y se llama "aristas" a las relaciones entre ellos. Las redes requieren dos nodos que estén relacionadas con un tercer nodo en común para que tengan más posibilidades de estar relacionados entre sí.

También, es importante destacar la existencia de distintos postulados que analizan el poder de las redes. Uno de ellos es la Teoría de los Seis Grados de Separación. La misma plantea que si tomamos dos personas diferentes del planeta y tratamos de ver si conocen gente en común llegaremos a la conclusión de que están conectadas por una cadena de personas conocidas que tiene, como máximo, cuatro intermediarios. Internet consigue realizar los seis saltos, de forma muy rápida, permitiendo conectarse con cualquier individuo del planeta (que esté conectado a Internet y desee compartir el concepto e intereses de la red social) casi instantáneamente. De esta manera, la red de conocidos de una persona podría extenderse a través de las redes de conocidos de sus conocidos y ser, virtualmente, conocido de toda la humanidad.

Una teoría de corte similar es la Teoría de los Diez Saltos, basada en que se puede conectar a una persona con las demás en el planeta en solamente 10 saltos: una persona conoce unas 100 perso- 
nas, y cada uno de ellos se relaciona, en promedio, con otras 100. Así, si la primera persona pide a sus amigos que pasen un mensaje a sus conocidos, casi inmediatamente la primera persona posee una red de 100 x 100=10000 conocidos a quienes podría estar pasando la información y entonces podría compartir cosas con ellos en Internet y fuera de ella. De esta manera, cada nivel de individuos amplía la cantidad de conocidos del nivel anterior de manera geométrica. Numerosos sitios se basan en esta teoría y han construido sitios Web que aglutinan a las personas en su entorno, formando interesantes redes sociales.

En la cultura tecnológica, la reflexividad se convierte en práctica, se convierte en comunicación

S. Lash

\section{Medios de comunicación y redes}

Sabemos acerca de la capacidad de influencia de los medios de comunicación sobre el público, es decir que los temas que quedan establecidos por la agenda settingl se convierten en cuestiones relevantes para el público. El punto central de esta teoría es la capacidad de los medios masivos de comunicación (Mass Media) para graduar la importancia de la información que se va a difundir, otorgándole prioridades para lograr un mayor impacto y/o determinada conciencia sobre una noticia. Queda claro que la información es un instrumento de poder y, en muchos casos concretos, de manipulación, capaz de persuadir e influir a la ciudadanía. Por lo tanto, se habla del Cuarto Poder porque efectivamente es un poder simbólico y social muy potente. Existen algunos autores que consideran que después de los poderes Legislativo, Ejecutivo y Judicial le precede la información, pero no es la información como tal, es decir dato, sino se trata del medio que dicta determinada comunicación o información; y ante este planteamiento es muy difícil cuantificar o enumerar a los medios, porque aparte de los sectores ya antes mencionados, existen intereses propios de la organización por ejercer determinado poderío. Se está hablando de un sistema de poder que intenta influir, crear ideologías, cambiar formas de pensamiento dentro de un período de transición histórica. Las reglas de juego de los medios de información las impone quién tiene el poder. Por cuestión de publicidad, los medios buscan entretener como principal prioridad a informar, porque la regla es ganar audiencia para ganar dinero. A partir de las Internet y de la aplicación de las Redes Sociales se estableció una nueva manera de de comunicarse o de identificar personas con las cuales se quiere entablar comunicación; la creación de contenidos individualizado nos permite vislumbrar el cambio radial en el uso de los medios de comunicación. Internet se está convirtiendo, de alguna manera, en el nexo que articula los distintos medios, sobre todo los multimedia. Con esto queremos decir que es “...el sistema operativo que permite interactuar y canalizar la información de qué pasa, dónde pasa, qué podemos ver (...) y ser, por tanto, el sistema conector interactivo del conjunto del sistema multimedia" (Castells, 1999)

La agenda va cambiando y hay muchas noticias que circulan antes por la Web y después llegan a los diarios. Los blogs se multiplican y ¿el periodismo se democratiza? Los medios están aban- 
donando su rol exclusivo de publisher y buscan otras nuevas formas de vida.

Las redes sociales, y en particular Facebook, ofrecen usar datos reales, verídicos, posibilitando así la revelación de las condiciones de producción de nuestros discursos y el desglose de nuestra subjetividad para transformarnos simplemente en nodos interrelacionados. Es por eso, que algunos afirman que la topología de la red termina facilitando la segregación y fragmentación social ya que cada actor decide sobre sí mismo pero carece de capacidad y oportunidad sobre cualquiera de los demás actores. Aquí estaríamos frente a una red distribuida, -término utilizado por Alexander Bard y Jan Söderqvist- quienes consideran que toda red distribuida es una red de iguales, aunque haya nodos más conectados que otros. Si la mayoría no sólo no simpatizara con una proposición, sino que se manifestara en contra de la misma, no podría evitar su realización. La democracia es, en este sentido, un sistema de escasez: la colectividad tiene que elegir entre una cosa y otra, entre un filtro y otro, entre un representante y otro.

Lash Scott nos permite analizar los principios estructurales de la Cultura Global de la Información al percibir que la masiva presencia de los flujos globales de la información y las comunicaciones ha disuelto el espacio separado y autónomo necesario para la reflexión y la crítica. Según Lash ya no se trata de la información: hoy, la clave es la comunicación. La primera generación de la sociedad de la información nos dió grandes empresas de información: la generación de Intel, Microsoft e IBM. La segunda generación ha producido las grandes compañías de comunicaciones, el crecimiento de las firmas del sector de la red como Cisco, Oracle, AOL, Netscapey Yahoo. Estas empresas proporcionan una infraestructura: una infraestructura de comunicaciones para Internet (Lash, 2005, p. 340). También afirma que la cultura global de la información depende del poder como exclusión. Se trata de exclusión con respecto al "circuito", a los medios de comunicación, a los flujos globales de información. Es lícito entonces, hablar de una "sociedad desinformada de la información" (Lash, 2005). Una producción tan racional puede resultar en una increíble irracionalidad de las sobrecargas de información, información errónea, desinformación e información descontrolada. La reflexividad tecnológica presume una fusión de la teoría y la práctica. Hay un aplanamiento de la interioridad del sujeto. Sin embargo, alega que la crítica aún es posible y para ejercerse, debe tener en cuenta, que la identidad, las prácticas y las asociaciones se organizan hoy a través del medio de la información. En consecuencia, la crítica de la sociedad debe ser crítica de la información. Y esta se convierte a la vez en una crítica del poder, que en nuestros días es informacional.

Entre otros autores que advirtieron el peligro de otorgar el estatuto de la información como único saber válido y a la informática como única ciencia que explique y modifique la realidad encontramos a Teodore Roszak; Con su libro El culto a la información, escrito a mediados de los ochenta, apunta a la forma en el que el hombre se posiciona ante las nueva tecnologías, mistificándolas y dotándolas de cualidades que aún hoy, exceden sus posibilidades, advirtiendo también, los peligros de la alineación del hombre cuando se somete a la lógica de las máquinas. Para Roszak, la revolución informática ha sido sobrevalorada y señala las consecuencias de esta situación: un grave peligro para la creatividad de la mente humana y el arte de pensar. 
La capacidad para transmitir es la capacidad para unir voluntades, para convocar, para actuar.

La capacidad para transmitir es una condición previa a la acción política David De Ugarte

$\mathrm{Al}$ igual que algunos animales, el hombre ha creado desde sus orígenes sistemas de convivencia basados en el grupo y en la comunidad y hoy más que nunca la composición de los tejidos sociales pasa a ser uno de los desafíos más importantes para recomponer a la sociedad misma. La red permite redescubrir la habilidad de los seres humanos de asociar palabras entre sí. Alrededor de esta capacidad subyace la semántica. La riqueza de relaciones se plasma en una red en las que las palabras altamente conectadas permiten encontrar con facilidad la relación sintáctica deseada.

La evolución de las Nuevas Tecnologías de la información y la Comunicación impusieron un nuevo paradigma comunicacional que renueva el valor de la palabra escrita. Los nuevos medios son pues participativos y ofrecen diferentes niveles de interacción. Se abre así el camino para una nueva instancia mediática: la experiencia cibersocial.

El esquema de Lucero (2003), esbozado a continuación, nos permite ver los diferentes lectores y niveles de interactividad.

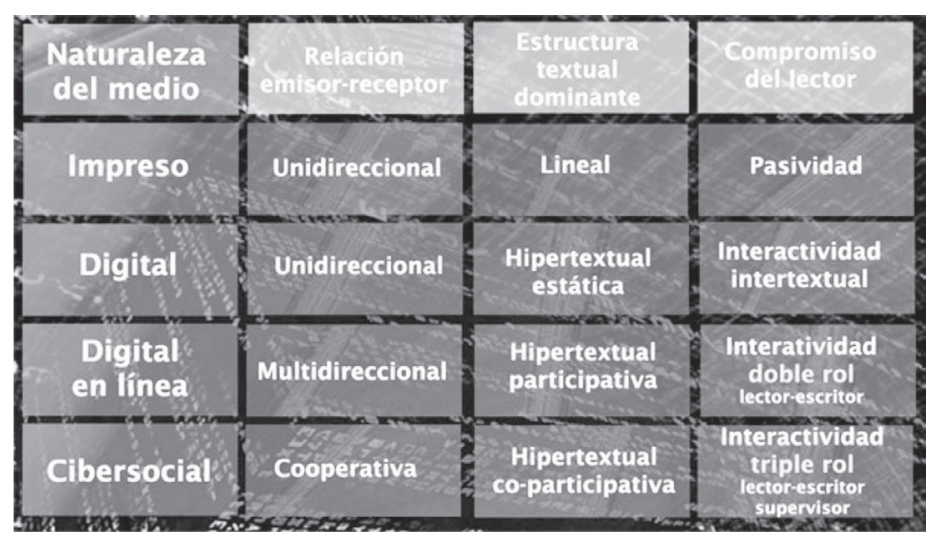

Figura 1. ¿Título? Fuente: Lucero, M. (2003). Entre el trabajo colaborativo y el aprendizaje colaborativo en Revista Ibeoamericana de Educación.

Por eso, podemos afirmar que las Nuevas Tecnologías están transformando nuestros comportamientos sociales y, como consecuencia, las formas de comunicación y relación de las personas. Si de vínculos hablamos, no podemos dejar de mencionar el hecho de que las redes sociales han demostrado ser herramientas efectivas en la política. Esto se debe a múltiples factores, pero por sobre todo se debe a que la transformación que está sufriendo la sociabilidad de base 
comunitaria física tradicional, por ejemplo existe una marcada disminución de la sociabilidad basada en el barrio que se suma a la crisis que atraviesan, según lo observado por Castells, las organizaciones tradicionales estructurales consolidadas tipo partido político.

\section{Obama: Yes We Did 2}

A continuación expondremos un caso por demás significativo que da cuenta, en alguna medida del poder de las tecnologías, en este caso, de las redes sociales para producir poder político. El uso de redes sociales en campaña es lógico y esperable si se tiene en cuenta un dato no menor: para el lenguaje de Facebook compartir es anunciar. Facebook puede dirigir la publicidad con mucha más precisión que un diario ya que estos últimos venden espacio publicitario a las empresas intentando que estas vendan sus productos a los lectores, afrontando el gasto de pagar a periodistas que proporcionen el contenido, mientras que Facebook obtiene su contenido gratis. Las tecnologías cosechan un poder político incalculable y las herramientas interactivas y redes sociales de la Web han fomentado la participación de la gente por vía electrónica dejando al descubierto las posibilidades que ofrecen estas redes para conseguir contenidos sin coste y para incrementar sus audiencias.

En efecto, en las últimas elecciones presidenciales que terminaron con el triunfo del primer presidente negro de EEUU, quedaron evidenciados los nuevos elementos que utilizaron para capturar el voto de los electores. La campaña ha revolucionado Internet como herramienta política. Los mensajes del aspirante demócrata han sido enviado on line por una masa de jóvenes aspirantes voluntarios de entre 18 y 21 año que actuaban en redes sociales.

Existieron múltiples factores que desencadenaron en el éxito de Obama, pero la movilización de energía comunitaria, por medio de sitios dedicados a las redes sociales, en donde la gente se comunica con grupos de su vecindario, se presentan voluntarios y se dona dinero fue sin lugar a dudas una de las claves. Durante toda la campaña, la popularidad de Obama ha ido creciendo, acercándose a los 7 millones de amigos solamente en Facebook. Los medios de comunicación tradicionales no sólo se han hecho eco de este fenómeno sino que se han apresurado por aumentar su propia presencia en esta red social. Cabe decir que al mando de la estrategia on line de Obama se encontraba el veinteañero, Chris Hughes, co-fundador de la red Facebook.

El éxito de la estrategia de la campaña ha sido saber detectar el grado de desencanto que, ante la política, tienen un gran segmento de la población como son los jóvenes electores que no se informan a través de los medios de comunicación clásicos, sino que se conectan permanentemente a las Redes Sociales. Gracias a ellas se logró una participación masiva en la campaña, que se materializaba en muy distintas formas. El equipo de Obama ha contado con una auténtica plataforma tecnológica exclusivamente diseñada para el activismo on line, utilizando la Web como escenario de administración.

Obama actuó muy hábilmente al considerar al elector como un adulto responsable, con capacidad de interactuar con el propio candidato y sus asesores empoderando, de esta manera al status de ciudadano y otorgándole la oportunidad de constituirse en auténticas comunidades de potenciales votantes que se implican y participan activamente en el comicio electoral.

Se fomentó la partición ciudadana y el debate electoral, dotando a la campaña de una mayor 
transparencia como consecuencia de una mejor información. Obama ha creado una comunidad en la red. Internet como instrumento de las personas puede acoger campañas de protesta logrando efectos positivos sobre la democracia al utilizar tecnología social para un efecto político decisivo.

Si bien no podemos negar que, para algunos, el caso Obama se perfila como un claro ejemplo de marketing electoral, nosotros más bien lo consideramos como un modelo que operó con el ciberactivismo ya que aquí se buscó la adhesión a una campaña cuyos objetivos y medios han sido diseñados estratégicamente a priori por un nodo organizador.

Según David de Ugarte podríamos definir ciberactivismo como

toda estrategia que persigue el cambio de la agenda pública, la inclusión de un nuevo tema en el orden del día de la gran discusión social, mediante la difusión de un determinado mensaje y su propagación a través del «boca a boca» multiplicado por los medios de comunicación y publicación electrónica personal (de Ugarte, 2007).

Cabe recordar que el ciberactivismo no es una técnica, sino una estrategia que cuenta con determinados elementos tales como el: discurso y la accesibilidad a la información. Esto último no es un tema menor ya que obliga a la búsqueda exhaustiva de todos los argumentos a favor y en contra de una postura determinada para ponerlos luego a disposición pública- y también implica un discurso en el que se debe resumir en pocas palabras el porqué debería inclinarse por ellos una persona normal, neutra. Sabemos que el tiempo es un valor preciado por eso el objetivo primordial es la maximización en la transferencia de información, quedando evidenciados los objetivos, los medios y las causas.

\section{Conclusión}

Este trabajo no tenía mas pretensión que la de ser un espacio reflexivo sobre los efectos derivados de la tecnología. Específicamente hablando, de la relación de Internet con la actividad política y los ciudadanos.

Internet se convirtió en mucho más que una herramienta, un medio de comunicación, de interacción y de organización social tecnológica. En palabras de Castells "los núcleos consolidados de dirección económica, política y cultural estarán también integrados en Internet” (Castells, 1999) ya que es un fenómeno que no le resulta ajeno a prácticamente ninguna cultura ni clase socioeconómica.

Queda a la vista el desfasaje entre la capacidad tecnológica y la política ya que el sistema político no está abierto a la participación, al diálogo constante con los ciudadanos y a la cultura de la autonomía y eso hace que estas tecnologías distancien a la política de la ciudadanía. No se trata de una condena a la modernidad tecnológica, muy por el contrario, porque si bien es cierto que en la sociedad contemporánea -o la sociedad informática como la denomina Mempo Giardinelli- se da la paradoja de que "... se conversa menos, y se discute poco. (...) Y si encima se impone un discurso único, sí que podemos estar en problemas". Pero una vez más eso no será culpa de las nuevas tecnologías, sino de los usos atrofiantes de ellas. “...Y a eso debemos resis- 
tirnos, incluso dentro de Internet" (Mempo Giardinelli, 2007: 98).

El desafío es, entonces, descubrir de qué manera Internet puede contribuir a la política, generando un ciudadano informado, activo y sobre todo capaz de utilizar de una manera efectiva a las herramientas que Internet contiene para promover un verdadero cambio en las relaciones de representación ciudadana, permitiendo que Internet sea el camino para un verdadero cambio social ya que “... Internet no es simplemente una tecnología: es el medio de comunicación que constituye la forma organizativa de nuestras sociedades, es el corazón de un nuevo paradigma socio técnico" (Castells, 1999).

El lector frente a la Nuevas Tecnologías se sitúa ante la posibilidad, de convertirse en protagonista, al asumir que la contribución individual refuerza el valor de las comunidades y que el conocimiento individual se enriquece y se construye en tanto forma parte del contexto de la sociedad del conocimiento. Se deben generan nuevos motores de búsqueda, dándole un lugar, a pesar de todo, al pensamiento crítico en la Era de la Información.

Será sólo a partir de la reordenación de los valores sociales, que sostienen las estructuras de poder, que se construyan redes de comunicación alternativas al poder, tanto como la reconstrucción crítica de nuestros propios marcos mentales.

Vivimos en el mundo de comunicación y redes de poder que se organizan a través de los sistemas de comunicación. Internet puede ser una excelente herramienta de participación ciudadana activa basada en la información. La capacidad que tenemos para crear una democracia informada interactiva no la estamos aprovechando. Estas herramientas y posibilidades van a cambiar a la democracia, y todos en mayor o menor medidas vamos a ser protagonistas de los cambios. Es que Internet es, ante todo, instrumento de libertad y espacio de comunicación autónoma. Sin dudas, y retomando a Castells, consideramos que la era digital irrumpe con divulgadores de información independientes y equipos de profesionales que configuran varias opciones de medios libre para la gente que quiere evitar la información manipulada de los medios tradicionales. No se trata sólo de saber utilizar la tecnología sino adquirir criterios de uso de la misma con libertad pero también con responsabilidad. En la sociedad de Internet lo complicado no es saber navegar sino saber dónde ir, dónde buscar lo que se quiere encontrar y qué hacer con lo que se encuentra. Y esto requiere Educación. Ya que, al fin y al cabo, "Internet es un instrumento que desarrolla pero no cambia los comportamientos, sino que los comportamientos se apropian de Internet, y por lo tanto, se amplifican y se potencian a partir de lo que son" (Castells, 1999).

\section{Notas}

1. Agenda-setting function, una de las teorías actuales más representativas de los medios de comunicación. En ella se estudia cómo los medios ejercen influencia en las audiencias mediante los temas considerados de mayor relevancia. El medio no decide por el público qué es lo que éste tiene que pensar u opinar sobre un hecho aunque sí decida cuáles son las cuestiones que van a estar en el candelero o en la opinión pública.

A este conjunto de contenidos se le denominará: la agenda. Desde el punto de vista de la Teoría de la agenda-setting, el término agenda se acuña en un sentido metafórico para expresar cómo las agendas o temas considerados relevantes por los medios pasan a ser subrayados también en las agendas de la audiencia. Las personas no sólo reciben información a través de los medios 
sobre determinados temas o asuntos que ocurren en el mundo y son considerados prioritarios, sino que también aprenden de ellos la importancia y el énfasis que les deben dar.

2. En referencia al libro escrito por Rahaf Harfoush, responsable de comunicación en Internet de Barak Obama.

\section{Referencias Bibliográficas}

Bona, Y. (2005). Reseña de Crítica de la información de Scott Lash. Barcelona: Athenea Digital, Universidad Autónoma de Barcelona.

Britto García L. (2005). Conciencia de América Latina. Intelectuales, medios de comunicación y Poder. Venezuela: Editorial Nueva Sociedad.

Canga Larequi, J. (1998). La Prensa y las Nuevas Tecnologías. Manual de la Redacción Electrónica. Madrid: Ediciones Deusto S.A.

Castells, M. (2009). Comunicación y Poder. España: Alianza Editorial.

(1999). Internet y la Sociedad Red, Lección inaugural del programa de doctorado sobre la sociedad de la información y el conocimiento. UOC.

De Ugarte, D. El poder de las redes. ISBN del libro electrónico 978-84-611-8873-4.

Debates IESA. Tecnología de Información: Electrónica y algo más. Revista publicada por el Instituto de Estudios Superiores de Administración (IESA) No 4, Vol. VIII, Caracas, Venezuela. (2002).

Faerman, J. (2009). Faceboom: el nuevo fenómeno de masas facebook. España: Barcelona Ediciones. Lash, S. (2005). Crítica de la Información. Bs. As: Amorrotu.

Lucero, M. (2003). Entre el trabajo colaborativo y el aprendizaje colaborativo en Revista Ibeoamericana de Educación.

Mempo Giardinelli. (2007). ¿Lecturas versus nuevas tecnologías? En Revista La Biblioteca, publicación de la Biblioteca Nacional de la República Argentina.

Pablos, J. P. (2001). La Red, es Nuestra. Barcelona: Ediciones Paidós Ibérica.

Pisani, F. (2002). Explorando al Ciberperiodismo Iberoamericano. ¿Y Ahora qué? México: Ediciones del CECSA.

Rodríguez Díaz. (2004). Teoría de la Agenda Meeting. Observatorio Europeo de tendencias sociales. Roszak, T. (1986). El culto a la información. España: Editorial Gedisa.

Summary: Historically man has had the constant need to communicate with their peers, express their ideas, feelings, leaving ultimately footprint itself.

Today we are witnessing a technological revolution that involves much more than the search for increasingly satisfying communication links. So is that advances in communication processes linked to technological developments allow us to talk about Information Technology and Communication.

Among these technologies we observed a significant other phenomenon: Social Networks. They have earned a place in a giddy way turning in promising business for companies and especially in human meeting places. Internet concentrates a variety of technologies that power the exchange and collaboration between users, thus promoting an increasing number and variety 
of networks, marked by the interaction that is, without doubt, one of their defining characteristics. The New Technologies of Information and Communication conquer mediated space where the written word reaches again a starring place, once occupied by audiovisual media.

Keywords: influence - information - media - power - social networks.

Resumo: Desde sempre o homem teve a necessidade constante de se comunicar com seus pares, de expressar suas idéias, sentimentos, de deixar, definitivamente, uma impressão de se mesmo. Hoje, nos assistimos a uma revolução tecnológica que é mais do que uma busca por satisfazer cada vez melhor seus vínculos comunicacionais. Por isso é que os avanços nos processos comunicativos ligados à evolução tecnológica nos permitem falar de tecnologias da informação e a comunicação.

Dentro destas tecnologias observa se um fenômeno significativo: as redes sociais, que hão ganhado um lugar de uma maneira veloz tornando-se em promissórios negócios para empresas e sobre tudo em lugares para encontros humanos.

Internet concentra uma variedade de tecnologias que potenciam o intercâmbio e a colaboração entre os usuários, fomentando desta maneira uma crescente quantidade e variedade de redes, signadas por a interação que é, sem dúvida, uma de suas características definitórias.

As novas tecnologias da informação e da comunicação conquistam o espaço midiatizado onde a palavra escrita logra, novamente, uma importância decisiva, que tinha sido deslocada pela relevância do audiovisual.

Palavras chave: influência - informação - meios - poder - redes sociais. 